\title{
Первая находка горчичного золота в золоторудных месторождениях Фенноскандинавского щита
}

\author{
Калинин А.А., Савченко Е.Э., Селиванова Е.А. \\ Геологический институт КНЦ РАН, Anamumbl, kalinin@geoksc.apatity.ru
}

\begin{abstract}
Аннотация. Горчичное золото на Оленинском месторождении развивается в зоне гипергенного преобразования руды за счет золотистого серебра (кюстелита) с примесью сурьмы. Нередко зерна горчичного золота имеют блочное строение, обусловленное изменением ориентировки и размера пор в матрице благородных металлов. Для горчичного золота характерна зональность, связанная с частичным выносом и соответствующим повышением содержания золота в матрице, а также с неравномерным распределением вещества, выполняющего поры. Микропоры в изученном горчичном золоте выполнены оксидами железа, соединениями сурьмы, таллия, хлоридами, бромидами и сульфидами серебра. Горчичное золото с хлоридами и бромидами в его составе ранее в мировой литературе не описано.
\end{abstract}

Ключевые слова: Горчичное золото, пояс Колмозеро-Воронья, Оленинское месторождение золота, кюстелит.

\section{The first finding of mustard gold in gold deposits of the Fennoscandian Shield}

\author{
Kalinin A.A., Savchenko Ye.E., Selivanova E.A. \\ Geological Institute of the KSC RAS, Apatity, kalinin@geoksc.apatity.ru
}

\begin{abstract}
Mustard gold in the Oleninskoe deposit forms in the zone of hypergenesis, it replaces küstelite with impurities of Sb. The mosaic structure of the mustard gold grains is due to different orientations and sizes of pores in the matrix of noble metals. Zonation in the mustard gold grains is connected with mobilization and partial removal of silver from küstelite, corresponding enrichment of the residual matter in gold, and also with the change in the composition of the substance filling the pores. Micropores in the mustard gold are filled with iron, antimony or thallium oxides, silver chlorides, bromides, and sulfides. Mustard gold with chlorides and bromides was not described earlier.
\end{abstract}

Keywords: Fennoscandian Shield; mustard gold; Kolmozero-Voronya belt; Oleninskoe deposit; küstelite.

\section{Введение}

Горчичное золото формируется в зоне гипергенеза золоторудных месторождений при окислении и разложении содержащих золото минералов - теллуридов, антимонидов и интерметаллидов (Некрасов, 1991, Гамянин и др., 1987, Литвиненко Шилина, 2017 и др.). Оно представляет собой ажурную тончайшую решетку из частиц (глобул) золота с порами исключительно мелкого размера (нередко менее 1 мкм), заполненными чаще всего кислородными соединениями $\mathrm{Fe}, \mathrm{Te}, \mathrm{Pb}, \mathrm{Cu}, \mathrm{Au}$, $\mathrm{Ag}, \mathrm{Sb}, \mathrm{Hg}$. То есть горчичное золото - это многофазное гетерогенное минеральное образование. Свое название это образование получило благодаря цвету, варьирующему от желто-коричневого до кирпично-красного, который обусловлен заполняющими ячейки гидроксидами железа, а также за землистую, рыхлую текстуру.

Поскольку размер глобул золота и пор составляет доли микрона, то микрозондовый анализ горчичного золота дает результат, усредняющий данные по каркасу из благородных металлов и по материалу, выполняющему поры. В составе горчичного золота устанавливаются золото, серебро, железо и другие металлы, а также кислород и, нередко, теллур и сера. Корректно разбраковать полученные данные по минеральным фазам часто невозможно, и по этой причине при анализе состава горчичного золота более важен качественный состав материала. Кроме того, для результатов анализа горчичного золота характерен дефицит суммы, обусловленный не только наличием кислородсодержащих фаз, но и пористостью анализируемого материала.

Выделения горчичного золота, как правило, ассоциируют с самородным золотом - горчичное золото нарастает на поверхность золотин, образует вростки в них, при этом само может обра- 
стать поздним высокопробным золотом. Реже отмечаются самостоятельные зерна горчичного золота (Некрасов, 1991).

Наиболее широко горчичное золото распространено в окисленных рудах золото-сурьмяных и золото-теллуридных месторождений (Некрасов, 1991), где оно встречается преимущественно в «кварцевой сыпучке» зоны окисления и вторичного сульфидного обогащения и в «железных шляпах» этих месторождений.

Как уже сказано выше, горчичное золото образуется при разложении теллуридов и антимонидов золота. Возможность развития горчичного золота при разложении калаверита подтверждена экспериментально (Zhao et al., 2009, Okrugin et al., 2014). Может формироваться горчичное золото и за счет богатых серебром сплавов золота и серебра с примесью сурьмы (Некрасов, 1991), но описано такое явление только в одном случае в золото-сурьмяных месторождениях Якутии (Гамянин и др., 1987).

Горчичное золото известно на месторождениях Дальнего Востока России, таких как Агинское, Озерновское, Асачинское, Гачинское на Камчатке (Кудаева, Андреева, 2014, Tolstykh et al., 2019), в Нижне-Мякитском рудно-россыпном поле в Магаданской области (Литвиненко Шилина, 2017), в Куранахском рудном поле (Кудаева, Андреева, 2014) и на месторождениях Сарылахское и Сентачанское (Амузинский и др., 2001) в Якутии. За рубежом горчичное золото описано на месторождениях Донгрин (Petersen et al., 2009) и Сандаованци (Zhao, Pring, 2019) в Китае, на месторождении Криван в Высоких Татрах в Словакии (Makovitsky et al., 2007), на золото-сурьмяном месторождении Харма в Боливии (Dill et al., 1995). В некоторых случаях на горчичное золото приходится до 50\% баланса золота (Petersen et al., 2009). Отметим, что перечисленные рудные объекты располагаются в мезозой - кайнозойских металлогенических зонах, где в вулканитах присутствуют эпитермальные месторождения золото-теллуридной и золото-сурьмяной формаций.

\section{Горчичное золото Оленинского месторождения}

Оленинское месторождение золота в зеленокаменном поясе Колмозеро-Воронья представляет собой рудный объект, нетипичный по своим минералого-геохимическим характеристикам для докембрийских зеленокаменных поясов. Здесь широко распространены соединения сурьмы, в том числе с серебром и золотом, минералы ряда золото-серебро богаты серебром (три из четырех генераций представлены золотистым серебром - кюстелитом) (Калинин и др., 2017). Попытки отыскать аналоги Оленинского месторождения в докембрийских комплексах мира не увенчались успехом.

Горчичное золото (термин используется ниже для различных вариантов соотношения золота и серебра в минерале, чаще всего состав сплава золота и серебра соответствует электруму) установлено в пробах, отобранных с полотна канавы, вскрывающей основное рудное тело месторождения и из ледниковых образований в борту канавы. Развивается горчичное золото за счет золотистого серебра (кюстелита), содержащего примесь сурьмы 1-3 масс. \%. Гипергенное происхождение горчичного золота на месторождении не вызывает особых сомнений (Kalinin et al., 2019)

Как известно, в приповерхностных низкотемпературных условиях серебро более подвижный металл, чем золото, и может быть мобилизован из золото-серебряных сплавов в кислотных условиях в виде комплексных соединений с $\mathrm{Cl}^{-}$или $\mathrm{Br}^{-}$(Пальянова, Колонин, 2007, Пальянова, 2008). По всей вероятности, именно такой процесс реализуется и при формировании горчичного золота на Оленинском месторождении. В исходных зернах кюстелита отношение $\mathrm{Au} / \mathrm{Ag}$ составляет 1/3. При выносе серебра и остаточном обогащении золотом образуется тончайшая решетка самородного золота с отношением $\mathrm{Au} / \mathrm{Ag}>1$ с микропорами, заполненными различным материалом.

В зависимости от материала, заполняющего поры (оценка состава минералов выполнена на энергодисперсионном спектрометре Bruker XFlash-5010, установленном на сканирующем микроскопе Leo-1450 методом бесстандартного анализа при помощи программного обеспечения QUANTAX 200), выделены следующие разновидности горчичного золота:

- с кислородными соединениями железа, сурьмы (а также в отдельных случаях таллия, свинца) (рис. 1, А-C); 

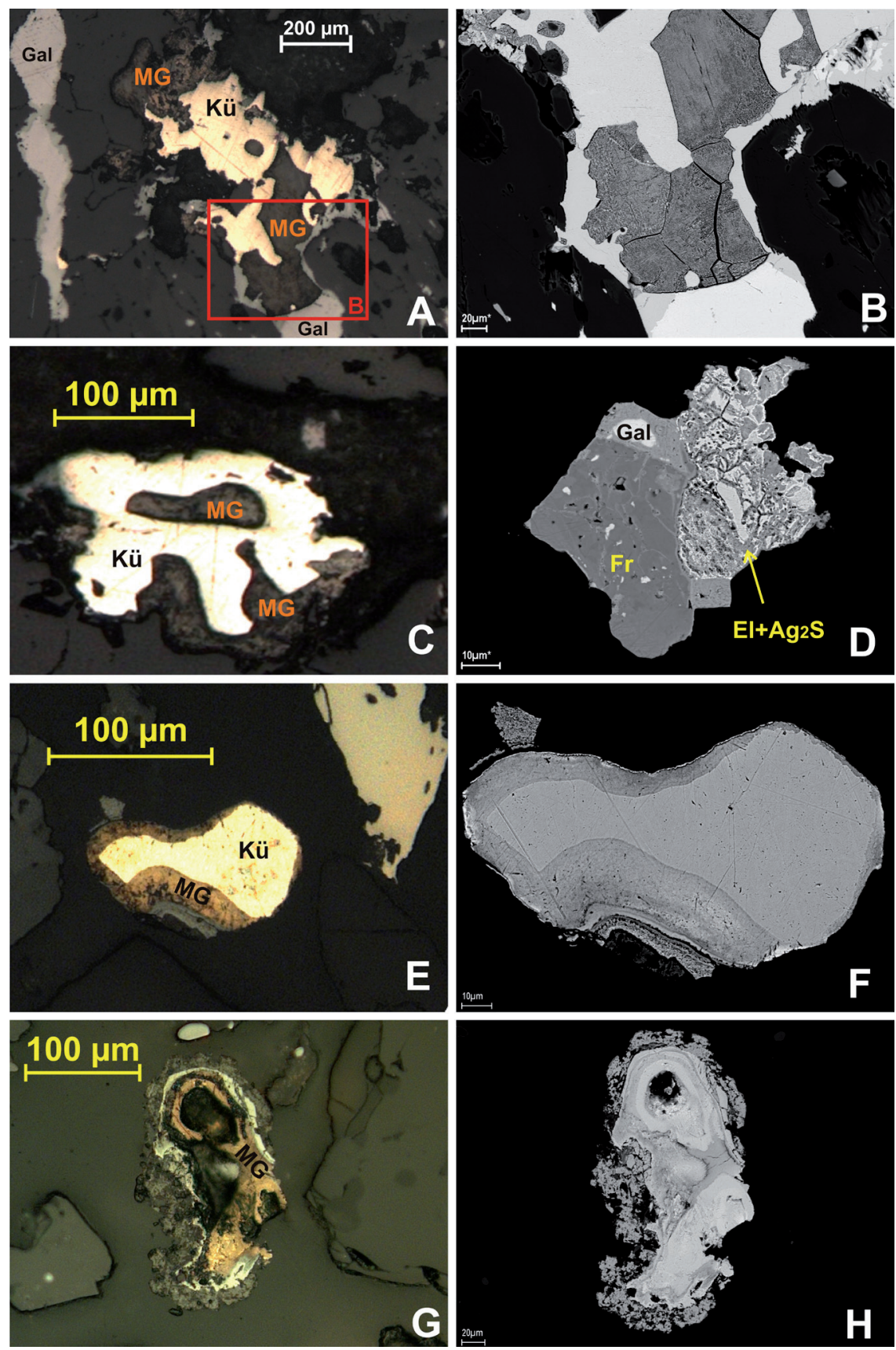

Рис. 1. Горчичное золото в рудах Оленинского месторождения.

Слева - фотографии аншлифов в отраженном свете, справа - изображения в обратно-рассеянных электронах. MG - горчичное золото, Kü - кюстелит, Gal - галенит, $\mathrm{Fr}$ - фрейбергит.

$\mathrm{A}-\mathrm{C}$ - горчичное золото с кислородными соединениями железа и сурьмы (качественно определены $\mathrm{Fe}, \mathrm{Sb}, \mathrm{Au}$, $\mathrm{Ag}, \mathrm{O}$, в малых количествах присутствуют также $\mathrm{Si}$ и Al); D - горчичное золото, представляющее собой смесь электрума и золотосодержащего акантита; E-F - кюстелит с каймой горчичного золота (состав в масс. \%: $\mathrm{Au} 51.0, \mathrm{Ag} 41.9, \mathrm{Br} 5.2, \mathrm{~S} \mathrm{0.8,} \mathrm{Sb} \mathrm{0.5,} \mathrm{Fe} \mathrm{0.2,} \mathrm{Cl} \mathrm{0.2,} \mathrm{As} \mathrm{0.2)} \mathrm{с} \mathrm{бромаргиритом;} \mathrm{G-H} \mathrm{-} \mathrm{горчичное} \mathrm{золото} \mathrm{(состав}$ в масс. \%: Au 33.1, Ag 52.8, Cl 12.8 Br 0.8, S 0.5) с хлораргиритом, с каймой ютенбогардтита (?) (серо-голубой) и хлораргирита (темно-серый).

Fig. 1. Mustard gold in the ores of the Oleninskoe deposit. On the left - photos of polished sections in the reflected light, on the right - back scattered electron images. MG - mustard gold, K - kstelite, Gal - galena, Fr - freibergite. $\mathrm{A}-\mathrm{C}$ - mustard gold with oxides of $\mathrm{Fe}$ and $\mathrm{Sb}(\mathrm{Fe}, \mathrm{Sb}, \mathrm{Au}, \mathrm{Ag}, \mathrm{O}$, and some $\mathrm{Al}$ and Si were defined qualitatively); D - mustard gold, an aggregate of electrum and gold-bearing acanthite; E-F - küstelite with a rim of mustard gold with bromargyrite (mustard gold composition in wt. \%: Au 51.0, Ag 41.9, Br 5.2, S 0.8, Sb 0.5, Fe 0.2, $\mathrm{Cl} 0.2$, As 0.2); G-H - mustard gold with chlorargyrite (mustard gold composition in wt.\%: $\mathrm{Au} \mathrm{33.1,} \mathrm{Ag} 52.8, \mathrm{Cl} \mathrm{12.8}$ $\mathrm{Br} 0.8$, S 0.5), with a rim of yutenbogaardtite (?) (gray-blue) and chlorargyrite (dark gray). 
- с сульфидами серебра (рис. 1, D);

- с хлоридами и бромидами серебра (рис. 1, Е-Н).

Горчичное золото с хлоридами и бромидами серебра, заполняющими поры, ранее в мировой литературе не описывалось. В зоне окисления Оленинского месторождения можно наблюдать постепенное замещение кюстелита горчичным золотом с формированием зональных зерен. Серебро, мобилизованное из кюстелита, заполняет поры в горчичном золоте в виде хлораргирита и бромаргирита, частично оно выносится и отлагается во внешних частях зерен горчичного золота в форме сульфидов и хлоридов. Формирующаяся зональность может быть сложной, более сильно измененными могут оказаться как внешние, так и внутренние зоны зерен. Наличие в составе горчичного золота двух фаз (сплава золота и серебра и хлораргирита) подтверждено рентгеновским анализом этих образований.

Зерна горчичного золота с порами, выполненными кислородными соединениями железа и сурьмы, нередко имеют блочное строение. Отдельные блоки отличаются ориентацией и размерами пор. Такое строение может быть связано с неоднородностью исходных зерен кюстелита. Известно, что для обогащенных серебром фаз ряда $\mathrm{Au}-\mathrm{Ag}$ нередко свойственно неоднородное, часто блочное внутреннее строение, в отличие от гомогенного золота средней и высокой пробности (Сахарова и др., 1982).

\section{Заключение}

Горчичное золото - относительно редкое минеральное образование, изученное в эпитермальных месторождения золота золото-теллуридной и золото-сурьмяной формаций в мезозойскокайнозойских вулканических поясах. В докембрийских месторождениях горчичное золото ранее описано не было, и выявлено нами впервые в составе руд месторождения Оленинского в северозападной части зеленокаменного пояса Колмозеро-Воронья. Впрочем, есть определенная вероятность, что горчичное золото присутствует в составе минерализации и некоторых докембрийских золото-теллуридных месторождений. В частности, при описании минерального состава руд метаморфизованного эпитермального месторождения Кутемаярви в южной части Финляндии упоминаются симплектитовые срастания самородного золота с теллуридами (Eilu, 2013), эти срастания также могут оказаться горчичным золотом.

Изученное горчичное золото месторождения Оленинское относится к его редкой разновидности, развивающейся не по теллуридам либо антимонидам золота, а по обогащенным серебром разностям интерметаллических соединений золота и серебра.

Работа выполнена в рамках темы НИР 0226-2019-0053.

\section{Литература}

1. Амузинский В.А., Анисимова Г.С., Жданов Ю.Я., Иванов Г.С., Кокшарский М.Г., Недосекин Ю.Д., Полянский П.М. Сарылахское и Сентачанское золото-сурьмяные месторождения: геология, минералогия, геохимия. М. Изд-во: МАИК «Наука/Интерпериодика». 2001. 218 с.

2. Гамянин Г.Н., Жданов Ю.Я., Некрасов И.Я., Леснова Н.В. «Горчичное» золото из золото-сурьмяных руд Восточной Якутии // Новые данные о минералах. 1987. № 34. С. 13-20.

3. Калинин А.А., Савченко Е.Э., Селиванова Е.А. Минералы благородных металлов в Оленинском рудопроявлении золота, пояс Колмозеро-Воронья (Кольский полуостров) // Записки РМО. 2017. №1. С. 43-58.

4. Кудаева Ш.С., Андреева Е.Д. Горчичное золото: характеристики, виды и химический состав / Материалы XIII Региональной молодежной научной конференции «Природная среда Камчатки». 15 апреля 2014 г., Петропавловск-Камчатский: Институт вулканологии и сейсмологии ДВО РАН. 2014. С. 17-30.

5. Литвиненко И.С., Шилина Л.А. Гипергенные новообразования золота из россыпных месторождений Нижне-Мякитского рудно-россыпного поля, северо-восток России // Руды и металлы. 2017. № 1. С.17-30.

6. Некрасов И.Я. Геохимия, минералогия и генезис золоторудных месторождений // М. Изд-во: Наука. $1991.302 \mathrm{c}$.

7. Пальянова Г.А., Колонин Г.Р. Геохимическая подвижность $\mathrm{Au}$ и $\mathrm{Ag}$ в условиях гидротермального переноса и отложения (термодинамическое моделирование) // Геохимия. 2007. № 8. С. 814-828. 
8. Пальянова Г.А. Физико-химические особенности поведения золота и серебра в процессах гидротермального рудообразования. Новосибирск. Изд-во: СО РАН. 2008. 221 с.

9. Сахарова М.С., Горшков А.И., Ряховская С.К, Трубкин Н.В. Новые данные об изоморфной смесимости золота и серебра в самородном золоте и его синтетических аналогах // ДАН СССР. 1982. Т. 264 . № 2. C. 457-460.

10. Dill H.G., Weiser T., Benhardt I.R., Kilibarda, R. The composite gold — antimony vein deposit at Kharma (Bolivia). Econ. Geol. 1995. V. 90. P. 51-66.

11. Eilu, P. Gold mineralisation in southwestern Finland. Geological Survey of Finland, Special Paper 52. 2012. P. 11-22.

12. Kalinin A.A., Savchenko Y. E., Selivanova E.A. Mustard Gold in the Oleninskoe Gold Deposit, KolmozeroVoronya Greenstone Belt, Kola Peninsula, Russia // Minerals. 2019. 9. 786. doi:10.3390/min9120786.

13. Makovicky E., Chovan, M.; Bakos, F. The stibian mustard gold from the Krivá `n Au deposit, Tatry Mts., Slovak Republic. N. Jahrb. Miner. Abh. 2007. 184. P. 207-215.

14. Okrugin V.M., Skilskaya E., Etschmann B., Pring A., Li K., Zhao J., Griths G., Lumpkin G.R., Triani G., Brugger J. Microporous gold: Comparison of textures from nature and experiments. Am. Mineral. 2014. 99. P. 1171-1174. DOI: 10.2138/am.2014.4792.

15. Petersen S.B.. Makovicky E., Juiling L., Rose-Hansen J. Mustard gold from the Dongping Au-Te deposit, Hebei province, People's Republic of China. N. Jb. Miner. Mh. 1999. No. 8. P. 337-357.

16. Tolstykh, N.D., Palyanova, G.A., Bobrova O.V., Sidorov E.G. Mustard gold of the Gaching Ore Deposit (Maletoyvayam Ore Field, Kamchatka, Russia). Minerals. 2019. 9. 489. Doi.org/10.3390/min9080489.

17. Zhao J., Pring A. Mineral Transformations in Gold-(Silver) Tellurides in the Presence of Fluids: Nature and Experiment. Minerals. 2019. 9. 167. Doi:10.3390/min9030167.

18. Zhao J., Bruger J., Gundler P.V., Xia F., Chen G., Pring A. Mechanism and kinetics of a mineral transformation under hydrothermal conditions: Calaverite to metallic gold. Am. Mineral. 2009. V. 94. P. 1541-1555. DOI: 10.2138/am.2009.3252. 